\title{
Selection of suitable distance education platforms based on human- computer interaction criteria under fuzzy environment
}

\author{
Aylin Adem $^{1} \cdot$ Erman Çakıt $^{1}$ (D) $\cdot$ Metin Dağdeviren $^{1}$
}

Received: 6 September 2021 / Accepted: 4 January 2022 / Published online: 17 January 2022

(C) The Author(s), under exclusive licence to Springer-Verlag London Ltd., part of Springer Nature 2022

\begin{abstract}
The rapid spread of the COVID-19 pandemic has affected not only the health industry but also the education sector. E-learning systems have recently become a compulsory part of all education institutions, including schools, colleges, and universities worldwide because of the COVID-19 pandemic crisis. The objectives of the current study were twofold: (1) to conduct an analytical approach for ranking of distance education platforms based on human-computer interaction criteria and (2) to identify the most appropriate distance learning platform for teaching and learning activities by using multicriteria decision-making approaches. Selection criteria were grouped into human-computer interaction-related criteria, such as ease of use, possibility of causing mental workload, user-friendly interface design, presentation method, and interactivity. In the selection procedure, a spherical fuzzy extension of Analytical Hierarchy Process was utilized to identify the weights of selection criteria and to rank distance education platforms. The results revealed that the most important criterion was the possibility of causing mental workload while the most preferable e-learning system was identified as "A3".
\end{abstract}

Keywords Fuzzy logic $\cdot$ MCDM $\cdot$ E-learning $\cdot$ Human-computer interaction

\section{Introduction}

In most countries, as well as in Turkey, educational institutions were closed for the duration of COVID-19, preventing students from continuing their regular studies. Face-to-face education was discontinued as a result of COVID-19 pandemic. Substitute approaches such as distance learning at home were used to ensure undisrupted instruction. E-learning grew in educational institutions all over the world about 15.4 percent per year without uncertainties or pressures on these institutions and students before the COVID-19 pandemic [1]. However, the situation has changed dramatically, since this study was performed during COVID-19. Recently, Öçal et al. [2] investigated the impact of the COVID-19 pandemic process on classroom instructors' and parents' ICT competencies and experiences. Similarly, Singh et al. [3] assessed the Indian

Erman Çakıt

ecakit@gazi.edu.tr; ecakit@gmail.com

1 Department of Industrial Engineering, Gazi University, 06570 Ankara, Turkey
Government's E-learning Initiatives, particularly during the COVID-19.

E-learning systems have recently become a compulsory part in all institutions of education including schools, colleges and universities around the world because of the COVID-19 pandemic crisis. At the same time, academicians are learning how to use distance education platforms. The transition to online mode, on the other hand, has raised several concerns about educational content [4]. Research by Zaman et al. [5] indicates that distance learning success depends on a variety of variables, such as study modules, user interface and support. Distance learning success regarding the quality of discussions can be improved using the beneficial effects of online participation. However, it is also well known that in an online community not all users are equally active and that there are indeed individuals who never actively participate- the so-called lurkers. Ebner and Holzinger [6] observed that visible interactions do not necessarily indicate learning.

There are more than one distance education platforms which were developed to fulfill the needs of both students and academicians. It is known that time duration while 
looking at screens increased dramatically due to the COVID-19 pandemic. Thus, it becomes more important that the system that is utilized in educational activities does not contribute to the mental workload of academicians.

The objectives of the current study were: (i) to conduct an analytical approach for ranking of distance education platforms based on human-computer interaction criteria and (ii) to identify the most appropriate distance learning platform for teaching and learning activities by using multi-criteria decision-making (MCDM) approaches. The considered selection criteria were grouped into humancomputer interaction-related criteria such as ease of use, possibility of causing mental workload, user friendly interface design, presentation method, and interactivity. It is expected that increasing the distance education performances of academicians, getting a higher quality education for students, and developing the interfaces of distance education platforms can contribute to more effective planning of education expenditures.

The rest of this study is organized in the following way. Section 2 provides an overview of the respective subjective literature. The detailed introduction of the usage of MCDM methods is provided in Sect. 3. Section 4 describes the application of the selected MCDM techniques and provides a comparative analysis of the outcomes. In the final section, we provide our findings and recommendations for further research.

\section{Background}

Despite the fact that e-learning has been evolving for many years, the evaluation of e-learning remains a critical challenge for businesses. The word "evaluation" is used for assessing the importance and value of products by people [7]. According to Tzenget al. [8], the primary goal of e-learning evaluation is to determine a course of action's effectiveness, efficiency, and appropriateness. The assessment of e-learning helps e-learning administrators and policy makers to distinguish positive and negative behavior, identify errors, correct mistakes, detect risks, and gain optimum investment that allows people to learn effectively [9].

The idea of e-learning is a concept which not only in the practice but also in the literature attracts much interest. MCDM approaches have been performed in the past to choose the best e-learning platform. Alptekin and Karsak [10] provided a decision modeling approach for assessing and addressing the challenge of E-learning product design. Their study's goal was to boost overall learner satisfaction. To do this, they used Quality Function Deployment (QFD) and fuzzy linear regression to identify appropriate E-learning products. Begičević et al. [11] developed a set of criteria for evaluating web-based learning. Then, using the AHP approach, they assessed e-learning practices in four stages: intelligence, design, choice, and implementation, and picked the best alternative in the selection stage. Bhuasiri et al. [12] initially identified a number of characteristics that contribute to the effectiveness of E-learning systems in developing nations. They then used AHP with the Delphi technique to analyze the relative relevance of variables across two stakeholder groups, which included ICT professionals and faculty members. Finally, their relevance has been identified and prioritized as essential success criteria.

Using fuzzy preference relations in AHP, the five main criteria for a successful E-learning application and sixteen sub-criteria were identified by Chao and Chen [13] to assess the relative value of these criteria in respect of each other. The primary goal of their research was to improve E-learning practice. AHP approach suggested by Colace et al. [14] to choose the most appropriate e-learning platform in terms of technology and teaching. They concluded that the hierarchy of the structure helps decision-makers to compare different e-learning platform features. Mastalerz [15] presented ELECTRE to address the issue of selecting an appropriate E-learning platform. Similarly, FAHP approach was performed to assess and select a practical and feasible e-learning platform [16]. During this method, a hierarchical model was applied to identify the priorities, criteria, and sub-criteria for selecting an e-learning platform. Yuen [17] suggested the Primitive Cognitive Network Process (P-CNP) as a multi-criteria assessment tool for deciding on the best e-learning platform. The key obstacles to the successful application of existing e-learning projects were poor interface design, inadequate technical support, and lack of IT skills [18]. The three key challenges in e-learning in Kenya include insufficient ICT resources, lack of technological expertise, and financial restrictions [19].

In another study, to assess the quality of E-learning websites, they used an "Axiomatic Design"-based technique for fuzzy group decision making [20]. The findings were then validated using fuzzy TOPSIS approach. Karasan and Erdogan [21] have conducted cognitive mapping extended with intuitionistic fuzzy sets in order to priority the selection factor of the e-learning platform. Infrastructure and ease of use are determined to be the most effective factors based on the results. Recently, a Fuzzy Vikor approach was employed for selecting alternatives among the three learning management systems accepted by colleges in Saudi Arabia [22]. The findings indicate that the most significant factors for decision makers in these organizations are both understandability and time behavior. Karagöz et al. [23] selected suitable learning management systems for organizations by using AHP methods. The 
authors used some factors including license cost, flexibility, security and market share for choosing process. Kant et al. [24] applied qualitative design to discuss the features, advantages and attributes of different popular learning management systems. In addition, a questionnaire-based online feedback was used to examine the learners' and academic counselors' perspectives. The authors suggest that employing the learning management systems by open and remote learning institutions can provide significant advantages and benefits not only for learners and teachers, but also for the open and remote learning system. Recently, Gong et al. [25] have proposed an integrated MCDM technique based on linguistic hesitant fuzzy sets (LHFSs) and the TODIM (an acronym in Portuguese of interactive and multi-criteria decision making) method to assess and choose the best e-learning website.In addition to these articles, a systematic literature review was conducted by Zare et al. [26], which may be regarded as the primary guide for researchers interested in decision making for e-learning.

Despite the fact that e-learning has been researched for many years, there is a research gap in academicians' use of e-learning platforms following the COVID-19 outbreak on higher education closure. In this study, unlike the approaches and the main criteria in the literature (Table 1), a different approach was provided for the first time by including academicians' perspective and human-computer interaction criteria under fuzzy environment. Humancomputer interaction helps designers, analysts and users discover system requirements from the design, while usability validates whether the system is effective, safe, easy to learn, easy to remember, easy to use, practical and user friendly [27].

On the basis of human-computer interaction, we determined the five main criteria as ease of use, possibility of causing mental workload, user friendly interface design, presentation method, and group work and interactivity. In the selection procedure, one of the newly developed fuzzy sets, spherical fuzzy sets and spherical fuzzy extension of AHP technique were utilized.

\section{Materials and methods}

\subsection{Spherical fuzzy sets and spherical fuzzy extension of AHP}

By combining Pythagorean and Neutrosophic fuzzy sets, Gündoğdu and Kahraman [28] developed and presented spherical fuzzy sets to the literature. Despite the fact that it is a relatively new set, SF sets have rapidly established themselves in the literature and have been included in a variety of MCDM methodologies. By focusing on the degrees of hesitancy, these sets really help the decisionmaker to examine decision-making procedures from a wider viewpoint. In this study, the spherical fuzzy extension of AHP was utilized to select the best e-learning system according to the human-computer interaction basis.

The spherical fuzzy sets (SFS) have membership, nonmembership, and hesitancy degree characteristics, much as the Pythagorean fuzzy sets. Let $E_{1}$ and $E_{2}$ be two universes. Let $\tilde{A_{s}}$ and $\tilde{B_{s}}$ of the universe of discourse $E_{1}$ and $E_{2}$ be as follows:

$\tilde{A_{s}}=\left\{x,\left(\mu_{\tilde{A_{s}}}(x), v_{\tilde{A_{s}}}(x), \pi_{\tilde{A_{s}}}(x)\right) \mid x \in E_{1}\right\}$

where $\mu_{\tilde{A}_{s}}(x): E_{1} \rightarrow[0,1], v_{\tilde{s}_{s}}(x): E_{1} \rightarrow[0,1], \pi_{\tilde{A}_{s}}(x): E_{1} \rightarrow[0,1]$ and

$0 \leq \mu_{\tilde{A}_{s}}^{2}(x)+v_{\tilde{A}_{s}}^{2}(x)+\pi_{\tilde{A}_{s}}^{2}(x) \leq 1 \quad \forall x \in E_{1}$

For each $x, \mu_{\tilde{A_{s}}}(x)$ shows the membership function, $v_{\tilde{A_{s}}}(x)$ represents the non-membership function, and $\pi_{\tilde{A_{s}}}(x)$ shows the hesitancy degree.

Similarly, $\tilde{B}_{s}=\left\{y,\left(\mu_{\tilde{A_{s}}}(y), v_{\tilde{A_{s}}}(y), \pi_{\tilde{A_{s}}}(y)\right) \mid y \in E_{2}\right\}$

where $\mu_{\tilde{B}_{s}}(y): E_{2} \rightarrow[0,1], v_{\tilde{B}_{s}}(y): E_{2} \rightarrow[0,1], \pi_{\tilde{B}_{s}}(y): E_{2} \rightarrow[0,1]$ and

$0 \leq \mu_{\tilde{B}_{s}}^{2}(y)+v_{\tilde{B}_{s}}^{2}(y)+\pi_{\tilde{B}_{s}}^{2}(y) \leq 1 \quad \forall y \in E_{2}$

For each $y, \mu_{\tilde{B}_{s}}(y)$ shows the membership function, $v_{\tilde{B}_{s}}(y)$ represents the non-membership function, and $\pi_{\tilde{B}_{s}}(y)$ shows the hesitancy degree [29]. The basic arithmetical operations for the SFS were developed by Gündoğdu and Kahraman [28].

- For summation operation of two SFS, the following formula is presented:

$$
\begin{aligned}
& \tilde{A_{s}} \oplus \tilde{B_{s}}=\left\{\left(\mu_{\tilde{A_{s}}}^{2}+\mu_{\tilde{B_{s}}}^{2}-\mu_{\tilde{A}_{s}}^{2} \mu_{\tilde{B_{s}}}^{2}\right)^{1 / 2}, v_{\tilde{A_{s}}} v_{\tilde{B_{s}}},\right. \\
& \left.\left(\left(1-\mu_{\dot{B}_{s}}^{2}\right) \pi_{A_{s}}^{2}+\left(1-\mu_{A_{s}}^{2}\right) \pi_{\vec{B}_{s}}^{2}-\pi_{A_{s}}^{2} \pi_{B_{s}}^{2}\right)^{1 / 2}\right\}
\end{aligned}
$$

- For multiplication operation of two SFS, the following formula is presented:

$$
\begin{aligned}
& \tilde{A_{s}} \otimes \tilde{B_{s}}=\left\{\mu_{\tilde{A}_{s}} \mu_{\tilde{B}_{s}},\left(v_{\tilde{A}_{s}}^{2}+v_{\tilde{B}_{s}}^{2}-v_{\hat{A}_{s}}^{2} v_{\tilde{B}_{s}}^{2}\right)^{1 / 2},\right. \\
& \left.\left(\left(1-v_{\vec{B}_{s}}^{2}\right) \pi_{\tilde{A}_{s}}^{2}+\left(1-v_{\hat{A}_{s}}^{2}\right) \pi_{\vec{B}_{s}}^{2}-\pi_{\hat{A}_{s}}^{2} \pi_{\vec{B}_{s}}^{2}\right)^{1 / 2}\right\}
\end{aligned}
$$

- For multiplication of a SFS by scalar $k(k>0)$, the following formula is presented: 
Table 1 Summary of main criteria and methodologies used for E-learning evaluation

\begin{tabular}{|c|c|c|}
\hline Author & Methodology & Main criteria \\
\hline $\begin{array}{l}\text { Begičević et al. } \\
\text { [11] }\end{array}$ & AHP & $\begin{array}{l}\text { "Strategic readiness for E-learning implementation" } \\
\text { "Basic ICT infrastructure for E-learning" } \\
\text { "Human resources" } \\
\text { "Legal and formal readiness for E-learning implementation" } \\
\text { "Specific ICT infrastructure for E-learning" }\end{array}$ \\
\hline $\begin{array}{l}\text { Alptekin and } \\
\text { Karsak [10] }\end{array}$ & QFD and fuzzy linear regression & $\begin{array}{l}\text { "Customer needs" } \\
\text { "E-learning product characteristics" }\end{array}$ \\
\hline Mastalerz [15] & ELECTRE & $\begin{array}{l}\text { "System's cost Technical support" } \\
\text { "Personalization Compatibility with other systems" } \\
\text { "Reports and statistics" } \\
\text { "Accessibility of learning materials" } \\
\text { "Evaluation mechanisms" }\end{array}$ \\
\hline $\begin{array}{l}\text { Bhuasiri et al. } \\
\text { [12] }\end{array}$ & Integrated (AHP) & $\begin{array}{l}\text { "Learners' characteristics" } \\
\text { "Instructors' characteristics" } \\
\text { "Institution and service quality" } \\
\text { "Infrastructure and system quality" } \\
\text { "Course and information quality" } \\
\text { "Extrinsic motivation" }\end{array}$ \\
\hline $\begin{array}{l}\text { Büyüközkan } \\
\text { et al. [20] }\end{array}$ & Integrated (TOPSIS) & $\begin{array}{l}\text { "Right and understandable content" } \\
\text { "Complete content" } \\
\text { "Personalization" } \\
\text { "Security" } \\
\text { "Navigation Interactivity" } \\
\text { "User interface" }\end{array}$ \\
\hline $\begin{array}{l}\text { Karasan and } \\
\text { Erdogan [21] }\end{array}$ & $\begin{array}{l}\text { Cognitive mapping extended with } \\
\text { intuitionistic fuzzy sets }\end{array}$ & $\begin{array}{l}\text { "Ease of use, Ease of exchanging learning with the others, Capability of controlling } \\
\text { learning progress, Network infrastructure, Availability of technical support staff, } \\
\text { Exam management system, Video and audio streaming, Pricing, Reporting, Access } \\
\text { (time and place), Security and privacy, Trialability, Interactivity level" }\end{array}$ \\
\hline $\begin{array}{l}\text { Karagöz et al. } \\
\text { [23] }\end{array}$ & AHP & "License cost, Flexibility, Security, Market share" \\
\hline Kant et al. [24] & $\begin{array}{l}\text { A questionnaire-based online } \\
\text { feedback }\end{array}$ & "Cost, Quality, Usage, Capacity, Budget" \\
\hline $\begin{array}{l}\text { Colace et al. } \\
\text { [14] }\end{array}$ & AHP & $\begin{array}{l}\text { "Management" } \\
\text { "Collaborative Approach" } \\
\text { "Management of interactive learning objects" } \\
\text { "Usability" } \\
\text { "Adaptation of learning path" }\end{array}$ \\
\hline $\begin{array}{l}\text { Chao and Chen } \\
\text { [13] }\end{array}$ & FAHP & $\begin{array}{l}\text { "E-learning material" } \\
\text { "Quality of web learning platform" } \\
\text { "Synchronous learning" } \\
\text { "Learning record" } \\
\text { "Self-learning" }\end{array}$ \\
\hline Liu et al. [16] & FAHP & $\begin{array}{l}\text { "Knowledge system" } \\
\text { "Learning system" } \\
\text { "Organizing system" }\end{array}$ \\
\hline
\end{tabular}


Table 1 (continued)

\begin{tabular}{|c|c|c|}
\hline Author & Methodology & Main criteria \\
\hline Yuen [17] & $\begin{array}{l}\text { Primitive Cognitive Network } \\
\text { Process }\end{array}$ & $\begin{array}{l}\text { "User friendliness" } \\
\text { "Knowledge sharing" } \\
\text { "Personalization" } \\
\text { "System performance" } \\
\text { "System extensibility" } \\
\text { "Mobility" }\end{array}$ \\
\hline $\begin{array}{l}\text { Ayouni et al. } \\
\text { [22] }\end{array}$ & Fuzzy Vikor & "Functionality, Reliability, Usability, Efficiency" \\
\hline Gong et al. [25] & $\begin{array}{l}\text { Integrated (Linguistic hesitant } \\
\text { fuzzy TODIM) }\end{array}$ & $\begin{array}{l}\text { "Navigation, Security, User Interface, } \\
\text { Personalization, Interactivity" }\end{array}$ \\
\hline
\end{tabular}

$$
\begin{aligned}
& k * \tilde{A_{s}}=\left\{\left(1-\left(1-\mu_{\tilde{A_{s}}}^{2}\right)^{k}\right)^{1 / 2}, v_{\tilde{A_{s}}}^{k},\right. \\
& \left.\left(\left(1-\mu_{\tilde{A_{s}}}^{2}\right)^{k}-\left(1-\mu_{\tilde{A_{s}}}^{2}-\pi_{\tilde{A_{s}}}^{2}\right)^{k}\right)^{1 / 2}\right\}
\end{aligned}
$$

\subsection{Calculation process of SF-AHP}

Saaty [30] presented the AHP approach, which is one the most popular of the various MCDM techniques. The logic of the AHP is based on linear algebra and pairwise comparisons of decision-making process parts. AHP is a hierarchical representation of a decision-making issue. Since the day it was developed, the AHP technique has been utilized in the solution of decision-making problems in many different fields including green ergonomics [31], Industry 4.0 [32], risk assessment [33, 34], weapon selection [35], safety management [36], and equipment selection [37].

The calculation steps in the application part were adapted from Gündoğdu and Kahraman [29], and are presented as follows:

Table 2 Linguistic scale for pairwise comparisons
As in every decision-making method, in this method, the boundaries of the decision problem (decision hierarchy) should be determined first. After that, expert or the expert group is asked to evaluate the criteria, if exist sub-criteria and alternatives. In SF-AHP technique, these evaluations are conducted by utilizing the scale given in Table 2 .

In order to check the consistency ratio of pairwise comparison matrices by applying the classical calculation way, the score index (as a crisp number) needs to know. To calculate the score index of AMI, VHI, HI, SMI linguistic expressions following equation is utilized:

$S I=\sqrt{\left|100 *\left[\left(\mu_{\tilde{A_{s}}}-\pi_{\tilde{A_{s}}}\right)^{2}-\left(v_{\tilde{A_{s}}}-\pi_{\tilde{A_{s}}}\right)^{2}\right]\right|}$

To calculate the score index of ALI, VLI, LI, SLI following equation is utilized:

$\frac{1}{S I}=\frac{1}{\sqrt{\left|100 *\left[\left(\mu_{\tilde{A_{s}}}-\pi_{\tilde{A_{s}}}\right)^{2}-\left(v_{\tilde{A_{s}}}-\pi_{\tilde{A_{s}}}\right)^{2}\right]\right|}}$

The conventional consistency calculating stages are used after determining the score index of each element in the pairwise comparison matrices. The acceptable limit for the maximum consistency ratio is $10 \%$. After checking and

\begin{tabular}{lll}
\hline Linguistic expressions & $(\mu, v, \pi)$ & Score index (SI) \\
\hline Absolutely more importance (AMI) & $(0.9,0.1,0.0)$ & 9 \\
Very high importance(VHI) & $(0.8,0.2,0.1)$ & 7 \\
High importance (HI) & $(0.7,0.3,0.2)$ & 5 \\
Slightly more importance(SMI) & $(0.6,0.4,0.3)$ & 3 \\
Equally importance (EI) & $(0.5,0.4,0.4)$ & 1 \\
Slightly low importance (SLI) & $(0.4,0.6,0.3)$ & $1 / 3$ \\
Low importance (LI) & $(0.3,0.7,0.2)$ & $1 / 5$ \\
Very low importance (VLI) & $(0.2,0.8,0.1)$ & $1 / 7$ \\
Absolutely low importance (ALI) & $(0.1,0.9,0.0)$ & $1 / 9$ \\
\hline
\end{tabular}


ensuring the all pairwise comparison matrix is consistent, fuzzy weights of criteria, sub-criteria and alternatives are computed. The Spherical Weighted Arithmetic Mean (SWAM) operator is employed for this process.

$$
\begin{aligned}
& \operatorname{SWAM}_{w}\left(A_{S 1}, \ldots, A_{S n}\right)=w_{1} A_{S 1}+w_{2} A_{S 2}+\cdots+w_{n} A_{S n} \\
& =\left\langle\left[1-\prod_{i=1}^{n}\left(1-\mu_{\hat{A}_{s i}}^{2}\right)^{w_{i}}\right]^{1 / 2}, \prod_{i=1}^{n} v_{\tilde{A}_{s i}}^{w_{i}}\right. \\
& \left.\left[\prod_{i=1}^{n}\left(1-\mu_{\hat{A}_{s i}}^{2}\right)^{w_{i}}-\prod_{i=1}^{n}\left(1-\mu_{\hat{A}_{s i}}^{2}-\pi_{\hat{A}_{s i}}^{2}\right)^{w_{i}}\right]^{1 / 2}\right\rangle
\end{aligned}
$$

where $w=1 / n$.

In order to compute global weights of sub-criteria, fuzzy local weights of sub-criteria and global weights of main criteria must be defuzzify with the help of following equation:

$S\left(\tilde{w}_{j}^{s}\right)=\sqrt{\left|100 *\left[\left(3 \mu_{\tilde{A_{s}}}-\frac{\pi_{\tilde{A_{s}}}}{2}\right)^{2}-\left(\frac{v_{\tilde{A_{s}}}}{2}-\pi_{\tilde{A_{s}}}\right)^{2}\right]\right|}$

The calculated crisp weights are normalized by utilizing the following equation:

$$
\bar{w}_{j}^{s}=\frac{S\left(\tilde{w}_{j}^{s}\right)}{\sum_{j=1}^{n} S\left(\tilde{w}_{j}^{s}\right)}
$$

The global weights of the sub-criteria are multiplied by the fuzzy priorities of the alternatives which are calculated with respect to the sub-criteria. This process is conducted by utilizing spherical fuzzy multiplication operator which is presented in the following formula:

$$
\begin{aligned}
& \tilde{A_{S_{i j}}}=\bar{w}_{j}^{s} \cdot A_{S_{i}} \\
& =\left\langle\left(1-\left(1-\mu_{A_{s}}^{2}\right)^{\bar{w}_{j}^{s}}\right) 1 / 2, v_{\tilde{A}_{s}^{s}}^{\bar{w}_{j}^{s}}\left(\left(1-\mu_{A_{s}}^{2}\right)^{\bar{w}_{j}^{s}}-\left(1-\mu_{A_{s}}^{2}-\pi_{A_{s}}^{2}\right)^{\bar{w}_{j}^{s}}\right)^{1 / 2}\right\rangle \forall i
\end{aligned}
$$

In order to rank the alternatives, the final spherical fuzzy scores of alternatives $(\tilde{F})$ must be calculated. For each alternative, the following formula applied to find the final fuzzy score of alternatives:

$$
\begin{aligned}
& \tilde{F}=\sum_{j=1}^{n} \tilde{A_{S_{i j}}}=\tilde{A_{S_{i 1}}} \oplus \tilde{A_{S_{i 2}}} \oplus \ldots . \tilde{A}_{S_{i n}} \forall i \\
& \tilde{A_{s_{11}}} \oplus \tilde{A_{s_{12}}}=\left\{\left(\mu_{\tilde{A_{s_{11}}}}^{2}+\mu_{\tilde{A_{s_{12}}}}^{2}-\mu_{\tilde{A_{s_{11}}}}^{2} \mu_{\tilde{A_{s_{12}}}}^{2}\right)^{1 / 2}, v_{\tilde{A_{s_{11}}}} v_{\tilde{A_{s_{12}}}},\right. \\
& \left.\left(\left(1-\mu_{\tilde{A_{s_{12}}}}^{2}\right) \pi_{\tilde{A}_{s_{11}}}^{2}+\left(1-\mu_{\tilde{A}_{s_{11}}}^{2}\right) \pi_{\tilde{A}_{s_{12}}}^{2}-\pi_{\tilde{A}_{s_{11}}}^{2} \pi_{\tilde{A}_{s_{12}}}^{2}\right)^{1 / 2}\right\}
\end{aligned}
$$

In light of this information, the followed path in this paper is shown in Fig. 1.
Determine the elements of decision problem

(i.e. Alternatives, Criteria and sub-criteria)

Take pairwise comparisons of element of decision problem

Calculate the Consistency Ratio of pairwise comparison matrix

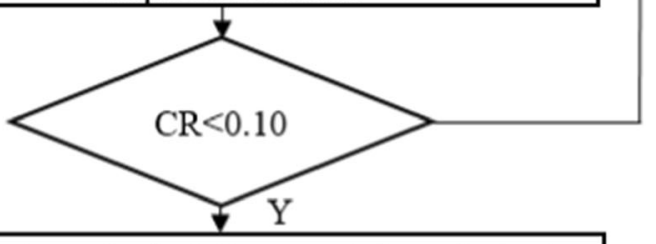

Calculate the spherical fuzzy weights of criteria and sub-criteria

Defuzzy these values and the calculate the global weights of sub-criteria

Calculate the spherical fuzzy priorities of alternatives with respect to each sub-criterion

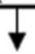

Multiply the global weights of sub-criteria and spherical fuzzy priorities of alternatives

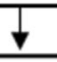

Calculate the final score of alternatives

Defuzzify these scores and rank the alternatives

Fig. 1 Study steps for proposed methodology

The calculation steps of the presented SF-AHP method were frequently utilized in the related literature (Gündoğdu and Kahraman [29] (renewable energy); Doğan [38] (mining technology selection); Sharaf [39], Unal and Temur [40] (supplier selection); Kieu et al. [41], Ayyıldız and Gumus [42] (location selection)). Although it is relatively new as a developed technique, it has frequently been used in the literature. Many different applications are available in the literature for further usage in integration with other MCDM techniques.

\section{Results and discussion}

\subsection{Selecting the best e-learning system}

In the selection procedure, in addition to the five main criteria and their sub-criteria, the actual names of the 
alternative e-learning systems are not given here. They are instead represented by A1, A2, A3, and A4, respectively. Behind the logic of human-computer interaction lies the system requirements for design in every activity related to human-computer interaction [27]. Thus, usability helps in the ergonomic evaluation of any computer-related system in terms of its effectiveness, safety, ease of learning, ease of remembering and use, degree of practical utility, and user-friendliness as the basis of human-machine interaction. The determined criteria and sub-criteria affecting the distance learning system selection on the basis of humancomputer interaction are shown in Fig. 2.

First of all, the main and sub-criteria are weighted. Alternatives will then be evaluated on the basis of subcriteria. As a result, the most suitable alternative will be selected on the basis of these criteria. Table 3 shows linguistic evaluations based on pairwise comparisons of the main criteria that the expert consensus.

The experts utilized the linguistic scale given in Table 2 in the evaluation steps. In total, 7 experts were included in the evaluation. Four of them were academicians using these software packages, and the remaining 3 were people with at least 5 years of experience in the sector. All the presented evaluation matrices were compromised matrices. By following the steps given in the methodology section, firstly the score indexes of the linguistic expressions were calculated by utilizing Eqs. (2) and (3). Then, with the help of the classical consistency index calculation steps, the consistency ratio of the pairwise comparison matrix was conducted. The consistency ratio (CR) was calculated as
Table 3 Pairwise comparison matrix for main criteria

\begin{tabular}{llllll}
\hline & C1 & C2 & C3 & C4 & C5 \\
\hline C1 & EI & SMI & SMI & HI & VHI \\
C2 & SLI & EI & SMI & HI & AMI \\
C3 & SLI & SLI & EI & HI & HI \\
C4 & LI & LI & LI & EI & SMI \\
C5 & VLI & ALI & LI & SLI & EI \\
CR $=0.090$ & & & & & \\
\hline
\end{tabular}

Table 4 Spherical fuzzy and defuzzified weights of main criteria

\begin{tabular}{lll}
\hline Main criteria & Spherical Fuzzy weights & Defuzzified weights \\
\hline C1 & $(0.661,0.329,0.262)$ & 0.250 \\
C2 & $(0.691,0.310,0.241)$ & 0.264 \\
C3 & $(0.572,0.419,0.282)$ & 0.213 \\
C4 & $(0.429,0.560,0.286)$ & 0.155 \\
C5 & $(0.338,0.655,0.264)$ & 0.119 \\
\hline
\end{tabular}

0.090. The evaluations for the main criteria are consistent because the calculated $\mathrm{CR}$ value is less than 0.10 . In Table 4, spherical fuzzy weights and deffuzzified weights are presented.

In calculating the spherical fuzzy weights of the main criteria, the SWAM operator shown in Eq. (3) was

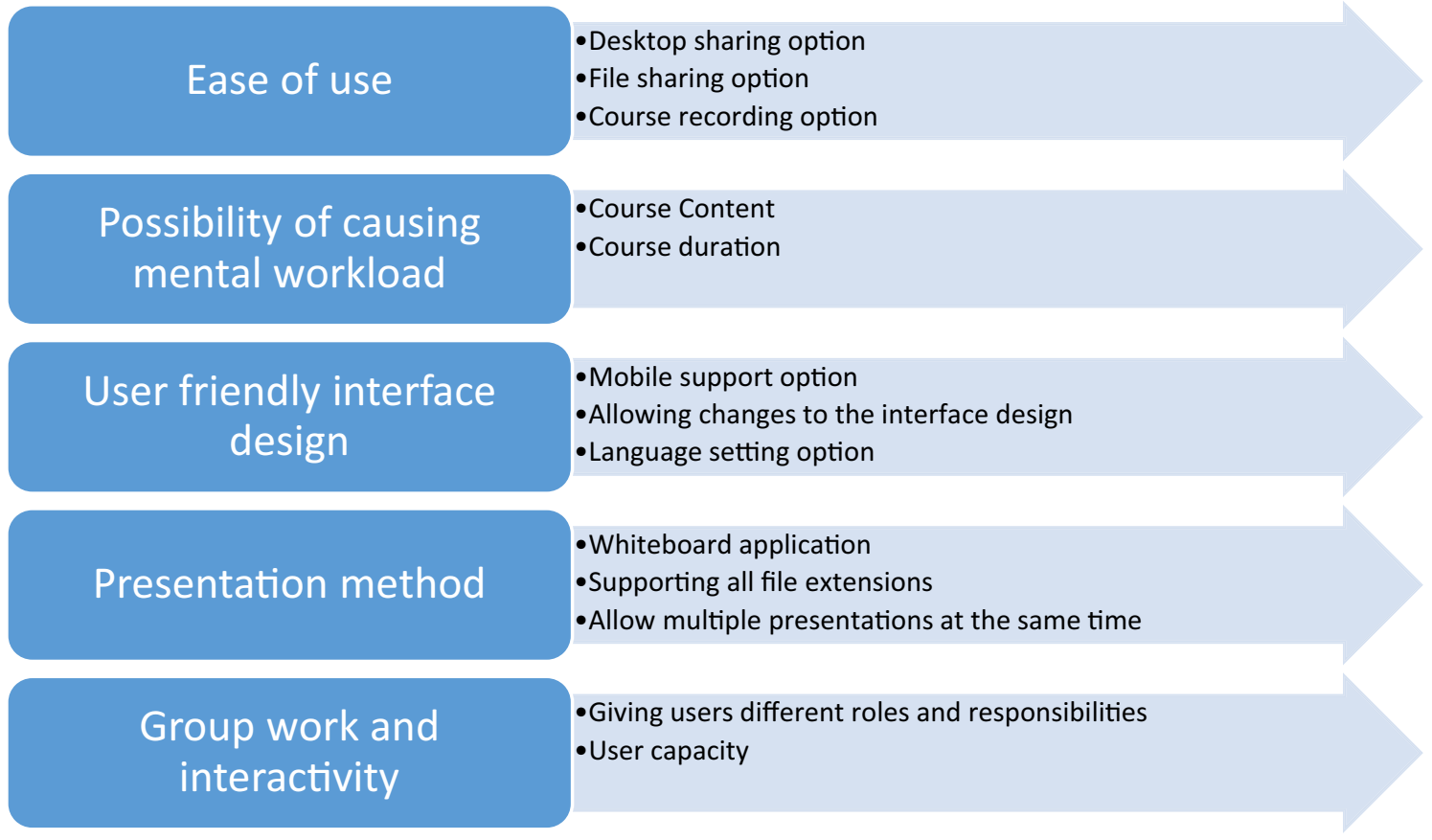

Fig. 2 The determined main and sub-criteria 
employed. In the defuzzification process of these spherical fuzzy weights, Eqs. (4) and (5) were utilized, respectively. According to Table 4, the most important selection criterion is determined as $\mathrm{C} 2$ that is the possibility of causing workload. After this criterion, the main criterion that affects the selection the most is the ease of use. As seen in the decision hierarchy, each of the main criteria in the problem has sub-criteria. For this reason, the weights of each sub-criterion should be calculated.

Table 5 shows the spherical fuzzy weights of sub-criteria. After calculating the weights of the main and subcriteria, the global weights of the sub-criteria are calculated. This is the multiplication of the global weights of the main criteria and the local weights of the sub-criteria.

Table 6 presents the local and global weights of subcriteria. According to Table 6, the most important subcriteria is determined as C21 that is presentation method. The least important sub-criterion is determined as $\mathrm{C} 42$ that is supporting all file extensions. At this stage of the calculation method, the alternatives were evaluated on the basis of sub-criteria. On the basis of each sub-criterion, the alternatives were compared in pairs and the consistency ratios of the comparison matrices were given under each matrix with the abbreviation CR. Fuzzy weights were determined by applying the SWAM operator (Eq. (2)) to

Table 5 Spherical fuzzy and defuzzified weights of sub-criteria

\begin{tabular}{lll}
\hline & Spherical fuzzy weights & Defuzzified weights \\
\hline C11 & $(0.612,0.363,0.302)$ & 0.409 \\
C12 & $(0.511,0.458,0.338)$ & 0.331 \\
C13 & $(0.411,0.552,0.321)$ & 0.261 \\
\hline & Spherical fuzzy weights & Defuzzified weights \\
\hline C21 & $(0.618,0.346,0.303)$ & 0.610 \\
C22 & $(0.417,0.529,0.331)$ & 0.390 \\
\hline & Spherical fuzzy weights & Defuzzified weights \\
\hline C31 & $(0.695,0.288,0.238)$ & 0.457 \\
C32 & $(0.491,0.482,0.321)$ & 0.305 \\
C33 & $(0.393,0.577,0.311)$ & $0 . .238$ \\
\hline & Spherical fuzzy weights & Defuzzified weights \\
\hline C41 & $(0.666,0.318,0.270)$ & 0.429 \\
C42 & $(0.363,0.607,0.285)$ & 0.218 \\
C43 & $(0.561,0.416,0.304)$ & 0.353 \\
\hline & Spherical fuzzy weights & Defuzzified weights \\
\hline C51 & $(0.554,0.400,0.351)$ & 0.557 \\
C52 & $(0.454,0.490,0.358)$ & 0.443 \\
\hline
\end{tabular}

Table 6 Local and global weights of sub-criteria

\begin{tabular}{llll}
\hline Main criteria & Sub-criteria & Local weights & Global weights \\
\hline C1 & & $\mathbf{0 . 2 5 0}$ & \\
& C11 & 0.409 & 0.102 \\
& C12 & 0.331 & 0.083 \\
C2 & C13 & 0.261 & 0.065 \\
& & $\mathbf{0 . 2 6 4}$ & \\
& C21 & 0.610 & 0.161 \\
C3 & C22 & 0.390 & 0.103 \\
& & $\mathbf{0 . 2 1 3}$ & \\
& C31 & 0.457 & 0.097 \\
& C32 & 0.305 & 0.065 \\
C4 & C33 & 0.238 & 0.051 \\
& & $\mathbf{0 . 1 5 5}$ & \\
& C41 & 0.429 & 0.066 \\
& C42 & 0.218 & 0.034 \\
C5 & C43 & 0.353 & 0.055 \\
& & $\mathbf{0 . 1 1 9}$ & 0.066 \\
& C51 & 0.557 & 0.053 \\
\hline & C52 & 0.443 & \\
& & &
\end{tabular}

Bold values are the weights of the main criteria

all these pairwise comparison matrices. These weights are shown in Table 7.

The fuzzy priorities of the alternatives were multiplied by the global weights of the sub-criteria, and the weighted priorities of the alternatives were determined. Equation (6) is utilized in this multiplying process. (The evaluation matrices of alternatives with respect to each sub-criterion are presented in Appendices.)

Table 8 shows the weighted preference relation values of the alternatives. Then, the weighted sums of the alternatives were calculated with Eq. (7). Table 9 shows the final priorities of alternatives and their scores.

Since the priorities obtained are in the fuzzy form, they should be clarified. According to the clarified values, the most suitable distance education alternative on the basis of human-computer interaction was determined as A3.

As can be seen in Table 9, the final score values of the alternatives were calculated very close to each other. For this reason, a basic sensitivity analysis was performed to measure the reaction of the alternatives to the change of criterion weights and to represent the robust results of applied solution. This sensitivity analysis was performed to express more clearly the effect of the criteria on the alternatives and to show how the rankings of alternatives change when the weight of each criterion group is greater than the others. These calculations were made by increasing the weight of the related main criterion by keeping the 
Table 7 The spherical fuzzy weights of alternatives with respect to sub-criteria

\begin{tabular}{llllll}
\hline & $\mathrm{C} 11$ & $\mathrm{C} 12$ & $\mathrm{C} 13$ & $\mathrm{C} 21$ & $\mathrm{C} 22$ \\
\hline A1 & $(0.675,0.313,0.253)$ & $(0.651,0.336,0.277)$ & $(0.713,0.283,0.250)$ & $(0.395,0.583,0.308)$ & $(0.637,0.346,0.277)$ \\
A2 & $(0.534,0.428,0.317)$ & $(0.571,0.412,0.303)$ & $(0.338,0.648,0.265)$ & $(0.658,0.313,0.279)$ & $(0.409,0.563,0.316)$ \\
A3 & $(0.372,0.605,0.289)$ & $(0.528,0.456,0.304)$ & $(0.571,0.412,0.303)$ & $(0.454,0.529,0.300)$ & $(0.536,0.443,0.328)$ \\
A4 & $(0.508,0.443,0.355)$ & $(0.348,0.629,0.268)$ & $(0.528,0.456,0.304)$ & $(0.588,0.372,0.327)$ & $(0.471,0.509,0.316)$ \\
\hline & C31 & $\mathrm{C} 32$ & $\mathrm{C} 33$ & $\mathrm{C} 41$ & $\mathrm{C} 42$ \\
\hline A1 & $(0.500,0.400,0.400)$ & $(0.387,0.586,0.299)$ & $(0.348,0.629,0.268)$ & $(0.372,0.605,0.289)$ & $(0.554,0.400,0.351)$ \\
A2 & $(0.500,0.400,0.400)$ & $(0.471,0.509,0.316)$ & $(0.651,0.336,0.277)$ & $(0.603,0.383,0.278)$ & $(0.632,0.336,0.302)$ \\
A3 & $(0.500,0.400,0.400)$ & $(0.571,0.412,0.303)$ & $(0.571,0.412,0.303)$ & $(0.708,0.283,0.230)$ & $(0.454,0.490,0.358)$ \\
A4 & $(0.500,0.400,0.400)$ & $(0.637,0.346,0.277)$ & $(0.528,0.456,0.304)$ & $(0.442,0.547,0.292)$ & $(0.423,0.526,0.339)$ \\
& \multicolumn{2}{c}{$\mathrm{C} 43$} & $\mathrm{C} 51$ & $(0.471,0.509,0.316)$ & $\mathrm{C} 52$ \\
\hline A1 & $(0.536,0.443,0.328)$ & $(0.409,0.563,0.316)$ & $(0.436,0.509,0.346)$ \\
A2 & $(0.471,0.509,0.316)$ & $(0.637,0.346,0.277)$ & $(0.417,0.529,0.331)$ \\
A3 & $(0.637,0.346,0.277)$ & $(0.536,0.443,0.328)$ & $(0.609,0.372,0.302)$ \\
A4 & $(0.409,0.563,0.316)$ & $(0.603,0.383,0.278)$ \\
\hline
\end{tabular}

Table 8 The weighted preference relation values of the alternatives

\begin{tabular}{llllll}
\hline & $\mathrm{C} 11$ & $\mathrm{C} 12$ & $\mathrm{C} 13$ & $\mathrm{C} 21$ & $\mathrm{C} 22$ \\
\hline A1 & $(0.25,0.89,0.11)$ & $(0.21,0.91,0.11)$ & $(0.21,0.92,0.09)$ & $(0.16,0.92,0.14)$ & $(0.23,0.90,0.12)$ \\
A2 & $(0.18,0.92,0.12)$ & $(0.18,0.93,0.11)$ & $(0.09,0.97,0.07)$ & $(0.30,0.83,0.15)$ & $(0.14,0.94,0.11)$ \\
A3 & $(0.12,0.95,0.10)$ & $(0.16,0.94,0.10)$ & $(0.16,0.94,0.10)$ & $(0.19,0.90,0.14)$ & $(0.18,0.92,0.13)$ \\
A4 & $(0.17,0.92,0.14)$ & $(0.10,0.96,0.08)$ & $(0.15,0.95,0.09)$ & $(0.26,0.85,0.16)$ & $(0.16,0.93,0.12)$ \\
\hline & $\mathrm{C} 31$ & $\mathrm{C} 32$ & $\mathrm{C} 33$ & $\mathrm{C} 41$ & $\mathrm{C} 42$ \\
\hline A1 & $(0.17,0.91,0.15)$ & $(0.10,0.97,0.08)$ & $(0.08,0.98,0.07)$ & $(0.10,0.97,0.08)$ & $(0.11,0.97,0.08)$ \\
A2 & $(0.17,0.91,0.15)$ & $(0.13,0.96,0.09)$ & $(0.17,0.95,0.08)$ & $(0.17,0.94,0.09)$ & $(0.13,0.96,0.07)$ \\
A3 & $(0.17,0.91,0.15)$ & $(0.16,0.94,0.10)$ & $(0.14,0.96,0.09)$ & $(0.21,0.92,0.08)$ & $(0.09,0.98,0.08)$ \\
A4 & $(0.17,0.91,0.15)$ & $(0.18,0.93,0.09)$ & $(0.13,0.96,0.08)$ & $(0.12,0.96,0.09)$ & $(0.08,0.98,0.07)$ \\
\hline \multicolumn{7}{r}{ C43 } & & $\mathrm{C} 51$ & & $\mathrm{C} 52$ \\
\hline A1 & $(0.14,0.96,0.09)$ & $(0.13,0.96,0.09)$ & $(0.11,0.97,0.09)$ \\
A2 & $(0.12,0.96,0.09)$ & $(0.11,0.96,0.09)$ & $(0.10,0.97,0.09)$ \\
A3 & $(0.17,0.94,0.09)$ & $(0.18,0.93,0.09)$ & $(0.16,0.95,0.09)$ \\
A4 & $(0.10,0.97,0.08)$ & $(0.15,0.95,0.10)$ & $(0.15,0.95,0.08)$ \\
\hline
\end{tabular}

local weights of the sub-criteria constant, and recalculating the global weights of each sub-criterion. In order to clearly show the effect of the criteria on the ranking of alternatives, the weight of the $\mathrm{C} 1$ criterion was taken as 0.90 (in this case the weights of remain criteria should be as follows: $\mathrm{C} 2=0.025, \mathrm{C} 3=0.025, \mathrm{C} 4=0.025, \mathrm{C} 5=0.025)$, and the global weights of the sub-criteria were determined according to these values and the final scores of the alternatives were calculated. Then, the weight of the $\mathrm{C} 2$ criterion was taken as 0.90 (in this case the weights of remain criteria should be as follows: $\mathrm{C} 1=0.025, \mathrm{C} 3=0.025$,
$\mathrm{C} 4=0.025, \mathrm{C} 5=0.025)$ and the final scores of the alternatives were obtained by repeating the same calculations. Similarly, the weights of C3, C4, and C5 criteria were taken as 0.90 and the rankings of the alternatives were recalculated respectively. The result of this calculation is shown in Table 10 and Fig. 3.

The obtained ranking according to the evaluations of the experts was as follows: A3-A1-A2-A4. In this ranking, the score values of the alternatives were determined to be quite close to each other. In the sensitivity analysis for the $\mathrm{C} 4$ and $\mathrm{C} 5$ criteria of the $\mathrm{A} 3$ alternative, it was ranked in the 
first place. According to the conducted analysis for the $\mathrm{C} 1$ and $\mathrm{C} 3$ criteria, the A3 alternative took the second place. Obviously, it is normal to obtain different rankings for different criteria. According to the obtained results, the applied methodology in this study produced robust results.

The main difference of this study from other studies in the literature is that it deals with the selection procedure to be applied in distance learning systems on the basis of human-computer interaction, that is, cognitive ergonomics. In this study, the AHP method was utilized, as is the general trend in the literature $[12,14,16]$. However, in this paper, the AHP method combined with spherical fuzzy sets, which is a newly developed set, was employed because it offers an effective calculation procedure by focusing on the hesitation degree of decision-makers [28]. Therefore, this paper differs from the studies in the literature in terms of both the handled criteria and sub-criteria sets and the utilized solution method.

\section{Conclusions}

With the concept of distance education rapidly taking hold across all education levels, the popularity of the platforms that provide these services has increased. In this study, distance learning platforms, which are more frequently used, especially with respect to the COVID-19 pandemic, are discussed from the viewpoint of human-computer interactions. Based on pandemic-associated effects, a phenomenon called digitalization in education has emerged, in which educators and students conduct educational activities through digital channels. At this point, educational institutions should choose and utilize one of

Table 9 Final priorities of alternatives and their scores

\begin{tabular}{lll}
\hline Alternatives & Spherical fuzzy priorities & Score index \\
\hline A1 & $(0.54,0.44,0.31)$ & 14.71 \\
A2 & $(0.53,0.45,0.31)$ & 14.45 \\
A3 & $(0.54,0.43,0.31)$ & 14.73 \\
A4 & $(0.52,0.45,0.32)$ & 14.12 \\
\hline
\end{tabular}

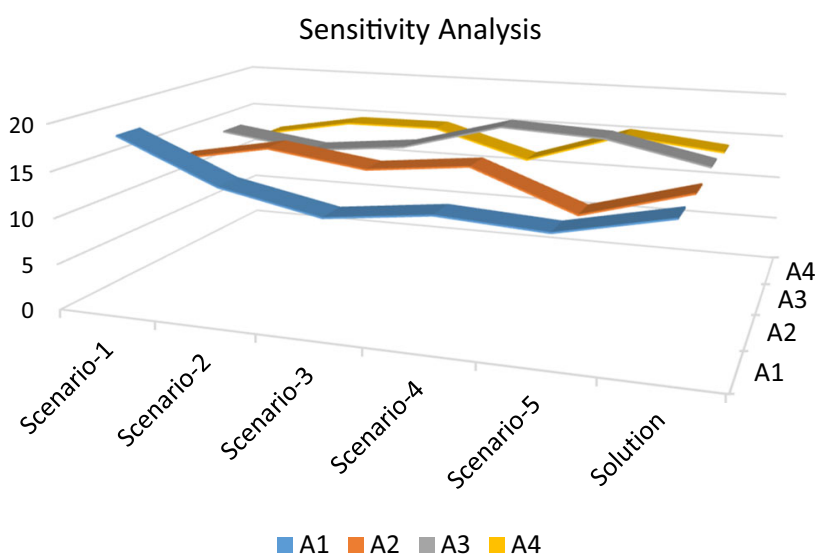

Fig. 3 Sensitivity analysis

the distance learning platforms on the market at almost every stage of education. Because these programs will have a very intense use case for trainers, considering this selection problem in terms of human-computer interaction distinguishes this study from other studies in the literature. The fuzzy scale utilized in this study has never been used in the selection of distance education platforms before. According to the obtained results, Program A3 stood out among the other three alternatives. The criteria that affected this selection are those that are important in terms of human-computer interaction. These include, among others, ease of use and contribution to mental workload. This study also aimed to enable the educational institutions that will make such a choice in practice to do so more easily. In future studies, it may be possible to expand the criteria and alternative sets by considering different characteristics of the selection problems and using different fuzzy scales. Moreover, it is possible to utilize different MCDM techniques by integrating them.

Table 10 Reacts of alternative rankings according to the criterion weight change

\begin{tabular}{llllll}
\hline Alternatives & $\begin{array}{l}\text { Highly important } \\
\text { criterion = C1 }\end{array}$ & $\begin{array}{l}\text { Highly important } \\
\text { criterion = C2 }\end{array}$ & $\begin{array}{l}\text { Highly important } \\
\text { criterion = C3 }\end{array}$ & $\begin{array}{l}\text { Highly important } \\
\text { criterion = C4 }\end{array}$ & $\begin{array}{l}\text { Highly important } \\
\text { criterion = C5 }\end{array}$ \\
\hline A1 & 18.53 & 13.95 & 11.73 & 13.00 & 12.32 \\
A2 & 13.80 & 15.78 & 14.27 & 15.45 & 11.26 \\
A3 & 14.92 & 13.44 & 14.57 & 17.62 & 17.08 \\
A4 & 12.69 & 14.66 & 14.76 & 11.62 & 15.29 \\
Ranking & (A1-A3-A2-A1) & (A2-A4-A1-A3) & (A4-A3-A2-A1) & (A3-A2-A1-A4) & $($ A3-A4-A1-A2) \\
\hline
\end{tabular}




\section{Appendices}

\begin{tabular}{|c|c|c|c|c|c|c|c|c|c|}
\hline $\mathrm{C} 11$ & A1 & A2 & A3 & A4 & $\mathrm{C} 32$ & A1 & A2 & A3 & A4 \\
\hline A1 & EI & $\mathrm{HI}$ & VHI & SMI & A1 & EI & SLI & LI & LI \\
\hline $\mathrm{A} 2$ & LI & EI & $\mathrm{HI}$ & EI & $\mathrm{A} 2$ & SMI & EI & SLI & LI \\
\hline $\mathrm{A} 3$ & VLI & LI & EI & SLI & A3 & $\mathrm{HI}$ & SMI & EI & SLI \\
\hline A4 & SLI & EI & SMI & EI & A4 & HI & HI & SMI & EI \\
\hline $\mathrm{CR}=0.05$ & & & & & $\mathrm{CR}=0.075$ & & & & \\
\hline $\mathrm{C} 12$ & A1 & A2 & A3 & A4 & C33 & A1 & A2 & A3 & A4 \\
\hline A1 & EI & SMI & SMI & VHI & A1 & EI & VLI & LI & LI \\
\hline $\mathrm{A} 2$ & SLI & EI & SMI & $\mathrm{HI}$ & A2 & VHI & EI & SMI & SMI \\
\hline A3 & SLI & SLI & EI & $\mathrm{HI}$ & A3 & $\mathrm{HI}$ & SLI & EI & SMI \\
\hline A4 & VLI & LI & LI & EI & A4 & $\mathrm{HI}$ & SLI & SLI & EI \\
\hline $\mathrm{CR}=0.087$ & & & & & $\mathrm{CR}=0.087$ & & & & \\
\hline $\mathrm{C} 13$ & A1 & A2 & A3 & A4 & $\mathrm{C} 41$ & A1 & A2 & A3 & A4 \\
\hline A1 & EI & AMI & SMI & SMI & A1 & EI & LI & VLI & SLI \\
\hline $\mathrm{A} 2$ & ALI & EI & LI & LI & A2 & $\mathrm{HI}$ & EI & SLI & $\mathrm{HI}$ \\
\hline A3 & SLI & $\mathrm{HI}$ & EI & SMI & A3 & VHI & SMI & EI & VHI \\
\hline A4 & SLI & $\mathrm{HI}$ & SLI & EI & A4 & SMI & LI & VLI & EI \\
\hline $\mathrm{CR}=0.071$ & & & & & $\mathrm{CR}=0.089$ & & & & \\
\hline $\mathrm{C} 21$ & A1 & $\mathrm{A} 2$ & $\mathrm{~A} 3$ & A4 & $\mathrm{C} 42$ & A1 & A2 & $\mathrm{A} 3$ & A4 \\
\hline $\mathrm{A} 1$ & EI & VLI & SLI & SLI & A1 & EI & EI & SMI & SMI \\
\hline $\mathrm{A} 2$ & VHI & EI & $\mathrm{HI}$ & EI & $\mathrm{A} 2$ & EI & EI & SMI & VHI \\
\hline A3 & SMI & LI & EI & LI & A3 & SLI & SLI & EI & EI \\
\hline A4 & SMI & EI & HI & EI & A4 & SLI & VLI & EI & EI \\
\hline
\end{tabular}

$\mathrm{CR}=0.0971$

$\mathrm{CR}=0.0342$

\begin{tabular}{llllllllll}
\hline C22 & A1 & A2 & A3 & A4 & C43 & A1 & A2 & A3 & A4 \\
\hline A1 & EI & HI & SMI & HI & A1 & EI & SMI & SLI & SMI \\
A2 & LI & EI & SLI & SLI & A2 & SLI & EI & LI & SMI \\
A3 & SLI & SMI & EI & SMI & A3 & SMI & HI & EI & HI \\
A4 & LI & SMI & SLI & EI & A4 & SLI & SLI & LI & EI
\end{tabular}

$\mathrm{CR}=0.0765 \quad \mathrm{CR}=0.0765$

\begin{tabular}{|c|c|c|c|c|c|c|c|c|c|}
\hline C31 & A1 & A2 & A3 & A4 & C51 & A1 & A2 & A3 & A4 \\
\hline A1 & EI & EI & EI & EI & A1 & EI & SMI & LI & SLI \\
\hline A2 & EI & EI & EI & EI & A2 & SLI & EI & LI & SLI \\
\hline A3 & EI & EI & EI & EI & A3 & $\mathrm{HI}$ & HI & EI & SMI \\
\hline A4 & EI & EI & EI & EI & A4 & SMI & SMI & SLI & EI \\
\hline
\end{tabular}

$\mathrm{CR}=0.0765$

\begin{tabular}{lllll}
\hline C52 & A1 & A2 & A3 & A4 \\
\hline A1 & EI & EI & SLI & LI \\
A2 & EI & EI & EI & LI \\
A3 & SMI & HI & SLI & SMI \\
A4 & HI & & & EI \\
CR $=0.099$ & & &
\end{tabular}




\section{Declarations}

Conflict of interest The authors declare that they have no conflicts of interest.

\section{References}

1. Toth-Stub S (2020) Countries Face an online education learning curve: the coronavirus pandemic has pushed education systems: online, Testing Countries' Abilities to Provide Quality Learning for All. Available online: https://www.usnews.com/news/bestcountries/articles/2020-04-02/coronaviruspandemic-tests-coun tries-abilities-to-create-effective-online-education Accessed from 17 Apr 2021

2. Öçal T, Halmatov M, Ata S (2021) Distance education in COVID-19 pandemic: an evaluation of parent's, child's and teacher's competences. Educ Inf Technol 26:6901-6921

3. Singh M, Adebayo SO, Saini M, Singh J (2021) Indian government E-learning initiatives in response to COVID-19 crisis: a case study on online learning in Indian higher education system. Educ Inf Technol 26:7569-7607

4. Sahu P (2020) Closure of universities due to coronavirus disease 2019 (COVID-19): impact on education and mental health of students and academic staff. Cureus 12(4):e7541

5. Zaman W, Ghosh P, Datta K, Basu PN (2012) A framework to incorporate quality aspects for e-learning system in a consortium environment. Int J Inf EducTechnol 2(2):159

6. Ebner M, Holzinger A, Catarci T (2005) Lurking: an underestimated human-computer phenomenon. IEEE Multimed 12(4):70-75

7. Oliver M (2000) An introduction to the evaluation of learning technology. J Educ Technol Soc 3(4):20-30

8. Tzeng GH, Chiang $\mathrm{CH}$, Li CW (2007) Evaluating intertwined effects in e-learning programs: a novel hybrid MCDM model based on factor analysis and DEMATEL. Expert Syst Appl 32(4):1028-1044

9. Roffe I (2002) E-learning: engagement, enhancement and execution. Qual Assur Educ 10(1):40-60

10. Alptekin SE, Karsak EE (2011) An integrated decision framework for evaluating and selecting e-learning products. Appl Soft Comput 11(3):2990-2998

11. Begičević N, Divjak B, Hunjak T (2007) Prioritization of e-learning forms: a multicriteria methodology. CEJOR 15(4):405-419

12. Bhuasiri W, Xaymoungkhoun O, Zo H, Rho JJ, Ciganek AP (2012) Critical success factors for e-learning in developing countries: a comparative analysis between ICT experts and faculty. Comput Educ 58(2):843-855

13. Chao RJ, Chen YH (2009) Evaluation of the criteria and effectiveness of distance e-learning with consistent fuzzy preference relations. Expert Syst Appl 36(7):10657-10662

14. Colace F, De Santo M, Pietrosanto A (2006) Evaluation models for e-learning platform: an AHP approach. In: Proceedings. Frontiers in education. 36th Annual Conference. IEEE, pp 1-6

15. Mastalerz MW (2010) Electre method for choosing an e-learning platform. In: 2010 Proceedings of VIth international conference on perspective technologies and methods in MEMS design. IEEE, pp $168-171$

16. Liu Q, Peng R, Chen A, Xie J (2009) E-learning platform evaluation using fuzzy AHP. In: 2009 international conference on computational intelligence and software engineering. IEEE, pp 1-4

17. Yuen KKF (2012) A multiple criteria decision-making approach for E-learning platform selection: the primitive cognitive network process. In 2012 computing, communications and applications conference. IEEE, pp 294-298

18. Mulhanga MM, Lima SR (2017) Podcast as e-learning enabler for developing countries: current initiatives, challenges and trends. In: Proceedings of the 2017 9th international conference on education technology and computers, pp 126-130

19. Tarus JK, Gichoya D, Muumbo A (2015) Challenges of implementing e-learning in Kenya: a case of Kenyan public universities. Int Rev Res Open Distrib Learn 16(1):120-141

20. Büyüközkan G, Arsenyan J, Ertek G (2010) Evaluation of e-learning web sites using fuzzy axiomatic design based approach. Int J Comput Intell Syst 3(1):28-42

21. Karasan A, Erdogan M (2020) Prioritization of influence factors for selecting E-learning systems. In: International conference on intelligent and fuzzy systems. Springer, Cham, pp 550-556

22. Ayouni S, Menzli LJ, Hajjej F, Madeh M, Al-Otaibi S (2021) Fuzzy Vikor application for learning management systems evaluation in higher education. Int $\mathbf{J}$ Inf Commun Technol Educ (IJICTE) 17(2):17-35

23. Karagöz E, Oral LÖ, Kaya OH, Tecim V (2017) LMS selection process for effective distance education system in organizations. KnE Soc Sci 1(2):343-356

24. Kant N, Prasad KD, Anjali K (2021) Selecting an appropriate learning management system in open and distance learning: a strategic approach. Asian Assoc Open Univ J 16(1):79-97

25. Gong JW, Liu HC, You XY, Yin L (2021) An integrated multicriteria decision making approach with linguistic hesitant fuzzy sets for E-learning website evaluation and selection. Appl Soft Comput 102:107118

26. Zare M, Pahl C, Rahnama H, Nilashi M, Mardani A, Ibrahim O, Ahmadi H (2016) Multi-criteria decision-making approach in E-learning: a systematic review and classification. Appl Soft Comput 45:108-128

27. Issa T, Isaias $P(2015)$ Usability and human computer interaction (HCI). Sustainable design. Springer, London, pp 19-36

28. Gündoğdu FK, Kahraman C (2019) Spherical fuzzy sets and spherical fuzzy TOPSIS method. J Intell Fuzzy Syst 36(1):337-352

29. Gündoğdu FK, Kahraman C (2020) A novel spherical fuzzy analytic hierarchy process and its renewable energy application. Soft Comput 24(6):4607-4621

30. Saaty TL (1988) What is the analytic hierarchy process? Mathematical models for decision support. Springer, Berlin, Heidelberg, pp 109-121

31. Adem A, Çakıt E, Dağdeviren M (2021) A fuzzy decision-making approach to analyze the design principles for green ergonomics. Neural Comput Appl. https://doi.org/10.1007/s00521021-06494-6

32. Adem A, Çakit E, Dağdeviren M (2020) Occupational health and safety risk assessment in the domain of Industry 40. SN Appl Sci 2(5):1-6

33. Adem A, Çolak A, Dağdeviren M (2018) An integrated model using SWOT analysis and Hesitant fuzzy linguistic term set for evaluation occupational safety risks in life cycle of wind turbine. Saf Sci 106:184-190

34. Adem A, Dağdeviren M, Çolak A, Kabak M (2016) Fuzzy prioritization approach for risks of wind turbine life cycle. Procedia Comput Sci 102:406-413

35. Dağdeviren M, Yavuz S, Kılınç N (2009) Weapon selection using the AHP and TOPSIS methods under fuzzy environment. Expert Syst Appl 36(4):8143-8151

36. Dağdeviren M, Yüksel İ (2008) Developing a fuzzy analytic hierarchy process (AHP) model for behavior-based safety management. Inf Sci 178(6):1717-1733 
37. Dağdeviren M (2008) Decision making in equipment selection: an integrated approach with AHP and PROMETHEE. J Intell Manuf 19(4):397-406

38. Dogan O (2021) Process mining technology selection with spherical fuzzy AHP and sensitivity analysis. Expert Syst Appl 178:114999

39. Sharaf IM (2021) Global supplier selection with spherical fuzzy analytic hierarchy process. Decision making with spherical fuzzy sets. Springer, Cham, pp 323-348

40. Unal Y, Temur GT (2020) Using spherical fuzzy AHP based approach for prioritization of criteria affecting sustainable supplier selection. In: International Conference on Intelligent and Fuzzy Systems. Springer, Cham pp. 160-168
41. Kieu PT, Nguyen VT, Nguyen VT, Ho TP (2021) A spherical fuzzy analytic hierarchy process (SF-AHP) and combined compromise solution (CoCoSo) algorithm in distribution center location selection: a case study in agricultural supply chain. Axioms 10(2):53

42. Ayyildiz E, Gumus AT (2020) A novel spherical fuzzy AHPintegrated spherical WASPAS methodology for petrol station location selection problem: a real case study for İstanbul. Environ Sci Pollut Res 27(29):36109-36120

Publisher's Note Springer Nature remains neutral with regard to jurisdictional claims in published maps and institutional affiliations. 